\title{
KONFLIK ANTARA AGAMA DAN SAINS DALAM PERSPEKTIF FILSAFAT SOSIAL
}

\author{
Dendi Sutarto \\ Prodi Ilmu Pemerintahan, Fakultas Ilmu Sosial dan Ilmu Politik \\ Universitas Riau Kepulauan, Batam, Indonesia \\ dendi_sutarto@yahoo.co.id
}

\begin{abstract}
Abstrak
Abad ketujuh belas merupakan periode perubahan sudut pandang yang sangat krusial, terutama kelahiran ilmu pengetahuan. Dua hal yang sangat menonjol dalam perkembangan ilmu pengetahuan baru tersebut adalah Dialoque (1632) karangan Galileo dan Principia (1687) karangan Newton. Pemikiran kedua tokoh ini menjelaskan asal-usul persoalan antara ilmu pengetahauan dan agama yang menjadi pusat perhatian. Dalam perkembangan ilmu pengetahuan, tentu muncul "drama dunia abad pengetahuan" di mana " dua ilmu pengetahuan baru Galileo dan dunia mesin Newtonian". Kemudian sampai pada bagaimana kontribusi posistif agama terhadap ilmu pengetahuan baru dan hal-hal yang menjadi konflik utama dalam pergulatan antara agama dan sains. Secara historis, bagaimana perbedaan ilmu pengetahuan baru pada abad ketujuh belas dengan ilmu pengetahuan baru abad pertengahan? Fokusnya adalah kombinasi baru penalaran matematis dengan observasi eksprimental. Satu abad sebelumnya Galileo, pentingnya penyederhanaan matematis telah di dukung oleh Copernicus. Skema Ptolemaic, yang mengasumsikan bahwa matahari dan planet berputar mengelilingi bumi. Namun menurut model Copernicus, di mana planet-planet dan bumi berputar mengelilingi matahari, sesuai dengan pengamatan yang keakuratan sebanding. Lebih jauh dalam bingkai sejarah kemajuan ilmu pengetahuan abad pertengahan serta kuatnya otoritas gereja yang melihat bahwa relasi ilmu pengetahuan dan agama adalah sebagai dua kutub yang berlainan sama sekali, yang cenderung melahirkan konflik antara agama dan saint, karena keduanya berangkat dari ruang lingkup yang berbeda. Namun perlu dipahami bahwa secara singkat pendekatan yang diambil oleh pemikiran abad pertengahan, oleh Galileo, dan kemudian oleh Newton seperti berikut: merode dalam ilmu pengetahuan, karakter alam, metode dalam teologi, Tuhan dan hubungan dengan alam, dan hubungan manusiua dengan alam.

Kata kunci: ilmu, agama, konflik, metodologi dan teologi.
\end{abstract}

\begin{abstract}
The seventeenth century was a very crucial period of change of view, especially the birth of science. Two things that are very prominent in the development of new science is dialoque (1632) by Galileo and Principia (1687) by Newton. The thinking of these two figures explains the origin of the problem between science of knowledge and religion which is the center of attention. In the development of science, it certainly appears "the world-century knowledge drama" in which "two new science of Galileo and the Newtonian machine world". It then comes to how the posi- tive contribution of religion to new science and the things that become the main conflict in the struggle between religion and science. Historically, how was the difference of new science in the seventeenth century with the new science of the middle ages? The focus is a new combination of mathematical reasoning with experimental observation. A century earlier Galileo, the importance of mathematics simplicity has been supported by Copernicus. The Ptolemaic scheme, which assumes that the sun and planets revolve around the earth. But according to the Copernican model, where planets and earth revolve around the sun, according to observations of comparable accuracy. Furthermore, in the historical framework of medieval science progress as well as the strength of the authority of the church which sees that the relation of science and religion are as two entirely different poles, which tend to give rise to conflict between religion and science, since both depart from different scopes. It should be understood, however, that briefly the approach adopted by medieval thought, by Galileo, and later by Newton as follows: merode in science, nature's character, methods in theology, God and relationship with nature, and human relationships with nature.
\end{abstract}


Keywords: science, religion, conflict, methods and theology.

\section{PENDAHULUAN}

Abad ketujuh belas merupakan periode perubahan sudut pandang yang sangat krusial, terutama kelahiran ilmu pengetahuan. Dua hal yang sangat menonjol dalam perkembangan ilmu pengetahuan baru tersebut adalah Dialoque (1632) karangan Galileo dan Principia (1687) karangan Newton. Pemikiran kedua tokoh ini menjelaskan asal-usul persoalan antara ilmu pengetahauan dan agama yang menjadi pusat perhatian. (Barbour, terj., Damayanti dan Ridwan, 2006: 19) Dalam perkembangan ilmu pengetahuan, tentu muncul "drama dunia abad pengetahuan" di mana "dua ilmu pengetahuan baru Galileo dan dunia mesin Newtonian". Kemudian sampai pada bagaimana kontribusi posistif agama terhadap ilmu pengetahuan baru dan hal-hal yang menjadi konflik utama dalam pergulatan antara agama dan sains.

Secara historis, bagaimana perbedaan ilmu pengetahuan baru pada abad ketujuh belas dengan ilmu pengetahuan baru abad pertengahan? Fokusnya adalah kombinasi baru penalaran matematis dengan observasi eksprimental. Satu abad sebelumnya Galileo, pentingnya penyederhanaan mamematis telah di dukung oleh Copernicus. Skema Ptolemaic, yang mengasumsikan bahwa matahari dan planet berputar mengelilingi bumi. Namun menurut model Copernicus, di mana planet-planet dan bumi berputar mengelilingi matahari, sesuai dengan pengamatan yang keakuratan sebanding.

Lebih jauh dalam bingkai sejarah kemajuan ilmu pengetahuan abad pertengahan serta kuatnya otoritas gereja yang melihat bahwa relasi ilmu pengetahuan dan agama adalah sebagai dua kutub yang berlainan sama sekali, yang cenderung melahirkan konflik antara agama dan saint, karena keduanya berangkat dari ruang lingkup yang berbeda. Namun perlu dipahami bahwa secara singkat pendekatan yang diambil oleh pemikiran abad pertengahan, oleh Galileo, dan kemudian oleh Newton seperti berikut: merode dalam ilmu pengetahuan, karakter alam, metode dalam teologi, Tuhan dan hubungan-Nya dengan alam, dan hubungan manusia dengan alam. 


\section{GARIS BESAR PANDANGAN ABAD PERTENGAHAN}

Suatu uraian ilmiah menurut pengertian Yunani terdiri dari: pengambaran teliti mengenai suatu gejala, penguraian (analisis) mengenai cirri-ciri utama gejala itu dan hubungan keduanya itu dengan prinsip-prinsip utama atau hukum-hukum yang diketemukan. Kemudian pemikiran tujuan dikaikkan dengan ide akal-budi yang menguasai alam semesta; dikaitkan pula dengan keteraturan dari segalasesuatu dalam suatu tata urut hirarkis dan dengan pemikiran serta kehendak Allah yang tertinggi. Pendapat bahwa segala sesuatu dalam alam semesta ini dapat dimengerti dan bahwa segala sesuatu diresapi kehendak Sang Pencipta yang belum kita ketahui, diterima baik oleh kaum terpelajar abad pertengahan.Allah di mengerti selaku penyebab pertama, bukan hanya dalam arti Pencipta kosmos.

Namun lebih jauh melainkan juga sebagai Daya Kehendak yang ikut bergerak dalam kecenderungan-kecenderungan yang lebih rendah. Jadi, kehendak dan rencana Allah dalam penciptaan merupakan keterangan terdalam mengenai ada, gerak atau perubahan segala sesuatu (Wilkes, dalam Adolf Heuken S.J dkk, 1974: 24). Baik Plato maupun Aristoteles menerima perlunya adanya Allah: Plato memeikirkan selaku ide atau bentuk form kebaikan yang tertinggi, sedangkan Aristoteles memeikirkan nya selaku penggerak pertama. Kemudian berkat kecerdasan Agustinus dari Hippo dan Thomas Aquinas, Gereja Abad Pertengahanberhasil mempertemukan ajaran Plato dan Aristoteles dengan pengertian Kristen mengenai Allah dan Bapa dari Jesus Kristus. Inilah sebabnya mengapa pemikiran abad pertengahan terutama bersifat deduktif.

Pengaruh cara berpikir Aristoteles sedemikian kuat, sehingga sangat sukarlah membedakan dua cara pemikiran dengan jelas dan sekaligus mempertahankan pola-pola pemikiran dan kepercayaan seperti lazim pada waktu itu. Dalam karya ilmiahnya Galileo terpaksa mengesampingkan segala pengertian mengenai sebab-sebab tujuan (Final cause). Sekalipun demikian, sampai ajalnya ia berhasil mempertahankan imannya akan Allah selaku penyebab pertama dan Bapa segala Sesutu (Wilkes, dalam Adolf Heuken S.J dkk, 1974: 26).

Suatu gagasan penting lainnya abad pertengahan adalah pola ilmu kosmologi atau model mengenai alam semesta. Pandangan ciptaan Ptolomeus dari Alexanderia (100-168) diterima orang pada zaman itu. Ptolomeus menempatkan bumi di titik pusat. Matahari dan planet-planet lain yang dikenal, berputar mengelilinginya. Planet-planet berputar pada sumbuhnya sendiri (perputaran rotasinya) dan pusat perputarannya itu berputar lagi 
mengelilingi bumi (perputaran revolusi).

Nampaknya pandangan ini cukup riil. Perhitungan ilmu astronomi yang masi kasar tidak menimbulkan keraguan mengenai pandangan ini. Keragu-raguan baru timpul ketika Copernicus mengajukan perhitungannya dan Tycho Brahe memperbaiki alat-alat perukuran. Dalam pandanga Ptolomeus, manusia menduduki tempat di pusat segala sesuatu dan manusia abad pertengahan percaya, bahwa kitab suci maupun ajaran Gereja mendukung pengertian ini. Sekalipun duni ilahi lebih sempurna dan berbeda koderatnya dari bumi, namun dunia dalam berbagai bidang dapat dipengaruhi olehnya (Wilkes, dalam Adolf Heuken S.J dkk, 1974: 26).

Hukum-hukum ilahi dapat diketemukan dalam sistem kosmos ini yang rencanakan dan diatur dengan baik. Sebab kosmos merupakan suatu gambaran tata moral dan rohani. Sistem ini dianggap pasti dan tak berubah dan dipandang sebagai tempat di mana setiap jiwa manusia dapat mengusahakan tujuan akhir. Demikian ajaran Agustinus, dengan kata lain, kosmos yang teratur ini diciptakan sebagai panggung, tempat drama pertentangan pribadi antara kebaikan dan kejahatan manusia. Dari sini pula pada akhirnya manusia akan dibangkitkan dan diadiliuntuk masuk ketempat yang sesuai dengan koderat jiwanya; surga atau neraka. Sandiwara-sandiwara misteri dari abad pertengahan seperti Divina Comedia karya Dante dan karya-karya Shakespeare, semuanya diwarnai pandangan ini. Ilmu pengetahuan yang baru timbul itu terpaksa menggoyang kepercayaan itu.

\section{AWAL KONFLIK AGAMA DAN SAINS}

Sejarah hubungan ilmu dan agama di Barat mencatat bahwa pemimpin gereja menolak teori Heliosentris Galileo atau teori Evolusi Darwin. Pemimpin gereja dengan otoritasnya membuat pernyataan yang berada di luar kopetensinya (Amin, 2003: 3)

"Tetapi karena saya telah diperintahkan oleh Majelis suci ini, dengan sama sekali mengabaikan opini palsu yang menegaskan bahwa matahari adalah pusat dan tak bergerak dan di larang untuk menganut, mempertahankan, atau pun mengajarkan doktrin palsu yang di katakana dengan cara apapun. Saya bersumpa, mengutuk dan merasa jijik dengan kesalahan-kesalahan dan bid'ah-bid'ah yang di katakana, dan secara umum setiap sekte dan kesalahan lain yang berlawanan dengan apa yang dikatakan gereja yang suci” (Galileo Galilei). (Davis, terj., Hamzah, 2002: 1)

Ilmu dan teologi mendekati pertanyaan-pertanyaan tentang eksistensi dari titik berangkat yang sama sekali berbeda. Sains didasarkan atas eksprimen dan observasi cermat 
yang memungkinkan teori-teori dibangun dan mempertahankan berbagai pengelaman yang berbeda. Regularitas-regularitas dalam proses kerja alam dicari, yang dengan penuh harapan akan mengungkap hokum-hukum fundamental yang mengatur perilaku materi dan gaya. Sebaliknya, agama di bangun di atas wahyu dan hakikat yang di terimah. Kemudian dogma agama yang mengklaim memuat kebenaran yang tidak dapat diubah, yang hamper tidak mungkin dapat dimodifikasi agar sesuai dengan ide-ide tersebut yang terus berubah (Davis, terj., Hamzah, 2002: 9).

Tesis yang akan muncul adalah bahwa di dalam bentuk logika umum ilmu pengetahuan dan agama, ketika di bentuk dengan baik, lebih memiliki kesamaan dari pada yang sering diduga, terutama pada intinya. Implikasi tesis ini adalah bahwa pandangan positivisme dan santisme yang mengagungkan ilmu pengetahuan dan merendahkan agama mengandung kesalahpahaman serius tentang alam, baik dari metode ilmiah maupun metode agama. Ilmu pengetahuan dan agama secara khusus memberikan penafsiran-penafsiran alternative tentang pengelaman, penafsiran ilmiah yang di dasarkan pada kausalitas, sedangkan aagama berdasarkan pada makna. Tetapi sejauh Roston III (2006: 1 - 2) melihat bahwa memilih ilmu pengetahuan dan agama baik sebagai metode, sebuah deskripsi tentang bagaimana seharusnya melakukan penyelidikan, mungkin tidak selalu, tetapi setidaknya di waktu sekarang sangat berkembang (Roston III, 2006: 2).

Sejarah ilmu pengetahuan ternyata, bahwa seorang Italia bernama Galileo Galilei (1564-1642) adalah tokoh yang paling menonjol dan akhirnya mendobrak tradisi kosmologi kuno. Lebih penting daripada penemuan-penemuan dalam ilmu astronomi adalah kemajuankemajuan azasi yang dikemukan Galileo dalam bidang mekanika. Dialah pendobrak yang menentukan kea rah penerangan secara baru yang mengganti cara berpikir Aristoteles. Keberatan-keberatan yang dikemukan Galileo terhadap sistem Aristoteles dalam tulisannya mengenai astronomi, tidaksetujui oleh mereka yang berwewenangdalam Gereja.

Perselisihan itu khusus disebabakan karena ia tidak mempergunakan bahasa Latin melainkan bahasa Italia dan karenanya di baca oleh masyarakat luas. Sekembalinnya Galileo di Pisa pada tahun 1610, ia diperingatkan agar jangan mengeluarkan pernyataan-pernyataan apapun yang menyinggung teologi. Ia meneruskan karyanya, dan pada tahun 1632 dia menerbitkan Dialogo sopra $i$ due massimi Sistem del mondo (Dialog yang mengenai dua Sestem Utama Dunia), suatu uraian popular mengenai pertentangan kosmologi lama dan baru. Ia terlampau keras mengencam kosmologi lama. Jadi Galileo diajukan ke pangadilan 
Garaja di Roma dan di paksa mengakui, bahwa pandangan-pandangannya bertentangan dengan ajaran resmi Gareja Katolik (Wilkes, dalam Adolf Heuken S.J dkk, 1974: 40).

Selama pemeriksaan yang menarik, Cardinal Bellarminus S.J. mengajukan agar kosmologi baru itu di perbolehkan di pergunakan hipotesa yang bermanpaat, asalkan belum di terima sebagai suatu gambaran yang pasti benar mengenai kenyataan. Sekalipun Galileo telah bersedia mempertimbangkan usul untuk menjaga nama itu, namun pengadilan menuntut agar ia menarik kembali pendapat-pendapatnya yang secara terang-terangan yang di kemukakannya dalam Dialogo. Pengadilan menjatuhkan hukuman agar dia berdiam diri. Sekalipun ia berada dalam hukumman itu, menentang yang tak tertundukkan ini berhasil menerbitkan karyanya yang terbesar Discorsi dimonstrazioni metematiche internoa due nouve scienze (pembicaraan pembuktian matematis mengenai dua ilmu baru) di Leiden (Nederland) pada tahun 1638.

Karya-karya Galileo yang di dasarkan eksperimen itu penting sekli, namun harus di akui juga bahwa kemajuan pemikirannya, misalnya keterangan perihal gerak, harus di mengerti dalam hubungan kemajuan yang telah di mulai sejak abad ke- XIV. Seperti gagasan pada tokoh-tokoh ganial yang lain, gagasan Galileo adalah: yang paling berhasil dalam masa pencaharian yang sudah lama berlangsung. Galileo sendiri bersifat keras juga dan ia tidak menghiraukan segala akibat yang terpaksa di hadapi ilmu teologi karena keteranganketerangan nya yang baru itu.

Johanes Kepler (157-1630) adalah tokoh ilmu pasti dan ahli astronomi bangsa Jerman yang hidup sejaman dengan Galileo. Kadang-kadang ke dua tokoh itu mengadakan surat menyurat, tetapi jalan pikiran dan hidup mereka tidak pernah bertemu. Berbeda dengan Galileo, Kepler adalah: seorang Kristen prostestan, seorang penulis ulung yang muskil, Kepler berkecipung dalam masalah-masalah ilmu pasti dan keselarasannya dari pada dalam pengamatan praktis atau ilmu mekanika. Dengan menggunakan data-data yang di wariskan oleh Tycho Brahe, Kepler berhasil menyempurnakan model alam semesta ciptaan Corpenicus. Dengan bantuan alat-alat ilmu pasti yang baru seperti: logaritma dan ilmu ukur segi tiga (trigonometri) yang di sempurnakan, Kepler menunjukkan bahwa planet-planet beredar dalam orbit elips dengan matahari sebagai salah satu titik pusatnya (Wilkes, dalam Adolf Heuken S.J dkk, 1974: 41). 


\section{RANAH KONFLIK AGAMA DAN SAINS ABAD MODERN}

Konflik agama dan sains di abad modern terjadi pada beberapa ranah, di antara wilayah konflik itu antara lain; dalam kosmologi yaitu pertentangan tentang asal usul perkembangan alam semesta. Kemudian pada ranah medic, seperti persoalan aborsi, KB, gays, seksualitas dan lesbian, dan juga terjadi konflik pada ranah religious practices, religious events. Sehingga berujung pada dimensi konflik berkaitan tentang kesatuan tuhan, kriteria kebenaran dan sampai pada persoalan siapa yang mengatur alam. Seringkali benturan antara agama (moralitas) dengan sains yang seolah bebas dari nilai-nilai moralitas kemanusiaan.

\section{Pola Hubungan Sains Dan Agama}

Ketika mendengar kata "sains" dan "agama", serta merta kita berpikir akan sejarah hubungan seru di antara keduanya. Namun catatan sejarah perjumpaan agama dan sains tidak hanya berupa pertentangan belaka (conflict), akan tetapi secara konstruktif sains dan agama mampu menjadi kekuatan yang sangat luar biasa. Pada kesempatan ini kita mencoba mengurai empat cara menurut Haught (2004: 1) yang khas dalam hubungan sains dan agama, yakni:

\section{Pendekatan Konflik}

Suatu keyakinan bahwa pada dasarnya sains dan agama tidak dapat dirujukkan. Alasan utama meraka bahwa agama jelas-jelas tidak dapat membuktikan kebenaran ajaranajarannya dengan tegas, pada hal sains bisa melakukannya. Agama mencoba bersikap diamdiam dan tidak mau memberi petunjuk bukti konkret tentang keberadaan tuhan. Di pihak lain, sains mau menguji semua hipotesis dan semua teorinya berdasarkan "pengelaman". Agama tidak bisa melakukan hal tersebut dengan cara yang bisa memuaskan pihak yang netral, klaim kaum skeptic; karena itu, mesta ada suatu "pertentangan" antara cara-cara pemahaman ilmiah dan pemahaman keagamaan.

Dalam catatan sejarah maupun pertimbangan-pertimbangan filosofis, keduanya tampak memperkuat keputusan yang serbakabur. Dari segi sejarah, kita perlu ingat kembali beberap contoh yang sangat jelas: penyiksaan oleh Gereja terhadap Galileo pada abad ke-17 dan tersebarnya agama serta teologi yang antiteori evolusi Darwin pada abad ke-19 dan 20. Lambatnya pemikiran keagamaan (teologi) menerima gagasan ilmiah seperti itu, dan fakta bahwa banyak orang yang beriman kepada Tuhan masih membenci mereka, memberi kesan bahwa agama tidak perna bisa akur dengan sains. 


\section{Pendekatan Kontras}

Suatu pernyataan bahwa tidak ada pertentangan yang sungguh-sungguh karena agama dan sains memberi tanggapan terhadap masalah yang sangat berbeda. Di lain pihak, banyak ilmuan dan teologi tidak menemukan adanya pertentangan antara agama dan sains. Menurut mereka masing-masingnya adalah abash (valid) meskipun hanya dalam batas ruang lingkup penyelidikan mereka sendiri yang sudah jelas. Kita tidak boleh menilai agama dengan tolak ukur sains, juga tidak boleh sebaliknya. Sebab pertanyaan yang diajukan oleh masing-masing sangatlah berbeda.

Menurut pendekatan ini, kesan bahwa agama berkonflik dengan sains hamper selalu berurat akar dalam sebuah kebingungan terdahulu, atau "peleburan" antara sains dengan satu sistem perecayaan religious ataupun kepercayaan sekuler. Maka untuk menghindari konflik, pendekatan kontraspun menandaskan bahwa kita harus terlebih dahulu menghindari percampurbauran sains dan keimanan sehingga menghasilkan sesuatu yang serba kabur. Ketidak mampuan teologi pada abad pertengahan untuk membeda-bedakan secara jelas agama dari sainslah yang membuat pemikiran-pemikiran Galileo tampak seperti bermusuhan di mata orang-orang beriman pada abad ke-17. Kegagalan Gereja untuk mengakui ranahranah sains dan agama yang terpisah telah menyebabkan para penguasa gereja itu mengutuk pemikiran baru Galileo, seakan-akan pemikiran itu merupakan pelanggaran kedalam tapal batas ranah sendiri.

\section{Pendekatan Kontak}

Suatu pendekatan yang mengupayakan dialog, interaksi, dan kemungkinan adanya "penyesuaian" antara sains dan agama, dan terutama mengupayakan cara-cara bagaimana sains ikut mempengaruhi pemahaman religius dan teologis. Cara menghubungkan agama dengan sains, dalam pendekatan ini tidak rela membiarkan dunia ini terpila-pila menjadi dua ranah yang ditetapkan oleh kubuh pendekatan kontras. Namun, dia juga tidak mau kembali lagi ke hrmoni yang dangkat. Dalam pendekatan peleburan. Pendekatan ini setuju bahwa sains dan agama jelas berbeda secara logis dan linguistic, tetapi dia tahu bahwa, dalam dunia nyata, mereka tidak bisa di kotak-kotakkan dengan mutlak, sebagaimana diandaikan oleh kubuh pendekatan kontras.

Pendekatan kontak mengemukakan bahwa pengatahuan ilmia dapat memperluas cakrawala keyakinan relegius dan bahwa perspektif keyakinan relegius dapat memperdalam 
pemahaman kita tentang alam semesta. Dia tidak berusaha membuktikan keberadaan tuhan berdasarkan sains, tetapi sudah merasa puas kalau menafsirkan penemuan-penemuan ilmia di dalam karangka makna keagamaan. Dia tidak berusaha menopang ajaran-ajaran keagamaan dengan mengacu pada konsep-konsep ilmia yang pada permukaannya, boleh jadi menunjuk secara lansung kepada seorang deseiner ilahi. Sudah tidak masanya lagi gagasan ilmia dapat di pergunakan untuk memperuat argumen bagi eksistensi tuhan.

\section{Pendekatan Konfirmasi}

Suatu perspektif yang lebih tenang, tetapi sangat penting; perspektif ini menyoroti cara-cara agama,pada tataran yang mendalam,mengundang dan menghidupkan segala kegiatan ilmiah. Diskusi kita tentang sains dan agama akan sangat subur jika di biarkan tetap pada tahap pendekatan pada kontak tadi; tetapi secara pribadi saya lebih suka untuk melangka lebih jauh lagi. Saya menghargai semua upaya untuk menemukan kecocokan antara sains dan agama, tetapi saya membayangkan sebuah relasi yang bahkan lebih erat lagi antara agama dan sains ketimbang yang di akui secara eksplisit oleh salah satu tiga pendekatan pertama. Di sini saya mengusulkan, juga dalam seluruh buku ini, bahwa agama, dengan suatu cara yang sangat mendalam, mendukung seluruh upaya kegiatan ilmia.

Tentu, agama tidak boleh di pakai untuk memperkuat cara-cara berbahaya di dalamnya pengatahuan ilmiah sering kali di terapkan dalam kenyataan. Usul saya bahwa agama pada dasarnya memperkuat kerinduan sederhana akan pengatahuan. Agama memperkuat dorongan yang bisa memunculkan sains. Saya menyebut pendekatan ke empat ini "komfirmasi" istilah ini sejajar dengan "memperkuat" atau "mendukung" karena dia mengatakan bahwa agama, kalau di murnikan secara hati-hati dari implikasi-implikasi yang menyesatkan, bisa mendukung sepenuhnya dan bahkan melandasi upaya ilmia dalam memberi makna kepada alam semesta ini.

Kemudian di sisi lian ruang untuk reintegrasi epistemologi keilmuan umum (science) dan agama mengandung arti perlunya dialog dan kerja sama antar disiplin ilmu umum dan agama yang lebih erat pada masa yang akan datang. Interkoneksitas dan sensitivitas ilmu sains dan agama perlu diupayakan secara terus menerus (Amin, dalam Abidin Baqir dkk, 2005: 261). Karena selama ini seringkali antara sains dan agama berjalan masing-masing, sehingga dengan kondisi seperti ini, maka agama melihat sains dengan pendekatan khas teologi, tanpa memahami ranah kerja sains. Belum lagi peran politik dan otoritas elit agama 
dengan mudah mengkalim salah dan benar.

Karena seringkali pemahaman terhadap sainslah yang salah, yang salah bukan sains semata, melainkan konsepsi mengenai sains itu sendiri (Smith, terj., Ary Budiyanto, 2003: 28). Kemudian kompleksnya problem yang dihadapi dalam hal relasi sains dan agama dalam catatan sejarah terutama abad pertengahan, justru diwarnai oleh persoalan politik, ekonomi dan elite agama (Gereja) seperti contah kasus Galileo dan berbagai ilmuanlainnya, Martin Luther yang mengecam sikap politisasi-ekonomi gereja yang menerbitkan surat pengampunan dosa. Sehingga di akhir makalah ini dari berbagai catatan sejarah muncul pertanyaan apakah benar konflik yang sesungguhnya adalah konflik sains dan agama?

\section{KESIMPULAN}

Dari beberapa kajian sejarah konflik sains dan agama di atas, setidaknya dapat ditarik benang merah bahwa dengan terjadinya peristiwa konflik ilmu dan agama di Barat dalam mencatat bahwa pemimpin gereja menolak teori Heliosentris Galileo atau teori Evolusi Darwin. Pemimpin gereja dengan otoritasnya menolak perkembangan kemajuan ilmu pengetahuan. Namun dalam kasus tentu persoalannya bukan hanya semata pertentangan pemahaman cara pandang khas sains dan agama, namun lebih lanjut adalah persoalan politik, ekonomi, karismatik gereja yang dilegitimasi oleh ajaran gereja sebagai kekuatan otoritas.

Namun tidak dipungkiri bahwa memang ilmu dan teologi mendekati pertanyaanpertanyaan tentang eksistensi dari titik berangkat yang sama sekali berbeda. Sains didasarkan atas eksprimen dan observasi cermat yang memungkinkan teori-teori dibangun dan mempertahankan berbagai pengelaman yang berbeda. Sebaliknya, agama di bangun di atas wahyu dan hakikat yang di terimah, sehingga akan erat hubungannya dengan pemahaman terhadap pesan pesan agama menurut tokoh agama ataupun institusi gereja.

Untuk mempertemukan, dan menghindari konflik antara sains dan agama, setidaknya dengan beberapa cara yang memungkinkan yaitu dengan pendekatan kontak dan integrasi keduanya sehingga memunculkan sintesis yang lebih produktif dan harmoni. Walaupun konflik agama dan sains masih menyisahkan berbagai persoalan, terutama konflik pada ranah cosmology, geology, medic, religious practices dan samapi pada konflik tentang aborsi, KB. Namun semua itu masih mempunyai ruang untuk dipertemukan setidaknya dalam ranah kemanusiaan. 


\section{DAFTAR PUSTAKA}

Abdullah, Amin dkk. (2003). Menyatukan Kembali Ilmu-ilmu Agama dan Umum, Upaya Mempertemukan Epistemologi Islam dan Umum. Yogyakarta: Suka Press.

Abdullah, Amin. (2005). Dari Pola Pendekatan Dikotomis-Atomistik ke Arah Integratif Interdisciplinary, dalam Zainal Abidin Bagir, dkk, Integrasi Ilmu dan Agama Interpretasi dan Aksi. Yogyakarta: MYIA kerjasama Mizan dan Suka Press

Barbour, Ian G. (2006). Issue in Science and Religion. Terjemahan Damayanti dan Ridwan, Isu Dalam Sains dan Agama. Yogyakarta: UIN Sunan Kalijaga.

Davis, Paul. (2002). God and the New Physics. Terjemahan Hamzah. Tuhan, Doktrin dan Rasionalitas, Dalam Debat Kontemporer. Yogyakarta: Fajar Pustaka Baru.

Haught, John F. (2004). Science and Religion: From Conflict to Conversation. Terjemahan Fransiskus Borgias, Perjumpaan Sains dan Agama: Dari Konflik ke Dialog. Bandung: Mizan.

Smith, Huston. (2003). Why Religion Matters: The Fate of the Human Spirit in an Age of Disbelief. Terjemahan Ary Budiyanto. Ajal Agama di Tengah Kedigdayaan Sains? Bandung: Mizan.

Roston, Holmes III. (2006). Ilmu dan Agama Sebuah Survai Kritis. Yogyakarta: UIN Sunan Kalijaga.

Wilkes, Keith. (1974). Religion and the Science. disadur ke dalam edisi Indonesia oleh Adolf Heuken S.J, dkk. Agama dan Ilmu-ilmu Pengetahuan. Jakarta:Gramedia. 